\title{
A Lei do Piso e a jornada: \\ o trabalho docente nos estados ${ }^{1}$
}

\author{
The Minimum Wage Law and the work hours: \\ the faculty work in the states
}

\section{La Ley del Piso y la jornada:}

el trabajo docente en los estados

MÁRCIA APARECIDA JACOMINI*

Universidade Federal de São Paulo, Guarulhos- SP. Brasil.

JUCA GIL**

Universidade Federal do Rio Grande do Sul, Porto Alegre- RS. Brasil.

EDIMÁRIA CARVALHO DE CASTRO***

Universidade Federal de São Paulo, Guarulhos- SP. Brasil.

\begin{abstract}
RESUMO:Com o objetivo de saber se a Lei 11.738/2008 (PSPN) estava sendo cumprida quanto à composição das jornadas de trabalho dos professores da educação básica pública das redes estaduais, analisamos sua duração e composição. Trata-se de pesquisa documental e bibliográfica, com base na legislação sobre planos de carreira vigentes em 2016 e na literatura acadêmica. Verificamos que havia grande diversidade na duração e composição das jornadas dos professores e que a maioria das redes estaduais não cumpria o PSPN na composição das jornadas previstas no plano de carreira.
\end{abstract}

* Doutora em Educação pela Faculdade de Educação da Universidade de São Paulo. Professora de graduação e pós-graduação do Departamento de Educação da Escola de Filosofia, Letras e Ciências Humanas da Universidade Federal de São Paulo. Desenvolve pesquisa sobre/em Políticas Educacionais e Gestão Escolar. E-mail: <jacominimarcia@gmail.com>.

** Doutor em Educação pela Faculdade de Educação da Universidade de São Paulo. É professor da Faculdade de Educação da Universidade Federal do Rio Grande do Sul. Pesquisa Políticas Educacionais. E-mail: <jucagil7@gmail.com>.

*** Licenciada em Pedagogia pela Universidade Federal de São Paulo. Membro do Grupo de Estudo e Pesquisa em Política Educacional e Gestão Escolar, vinculado ao Departamento de Educação da Escola de Filosofia, Letras e Ciências Humanas da Unifesp. E-mail: <edimaria_castro@hotmail.com>. 
Palavras-chave: Trabalho docente. Jornada de trabalho. Educação básica. Lei do Piso.

\begin{abstract}
In order to know if Law 11.738 / 2008 (PSPN) was being complied as far as the composition of the working days of teachers of public basic education of the state systems, we analyzed their length and structure. This is a documentary and bibliographic research, based on the legislation on career plans current in 2016 and in the academic literature. We verified that there was great diversity in the length and structure of the teachers' journeys and that most of the states systems did not fulfill the PSPN in the composition of the labor days planned in the career plan.
\end{abstract}

Keywords: Faculty work. Work hours. Basic education. Minimum Wage Law.

RESUMEN: Con el objetivo de saber si la Ley 11.738/2008 (PSPN) se estaba cumpliendo con respecto a la composición de las jornadas de trabajo de los docentes de la educación pública básica de las redes estatales, analizamos su duración y composición. Esta es una investigación documental y bibliográfica, basada en la legislación sobre planes de carrera vigentes en 2016 y en la literatura académica. Verificamos que había una gran diversidad en la duración y composición de las jornadas de los maestros, y que la mayoría de las redes de los estados no cumplían con el PSPN en la composición de las jornadas laborales previstas en el plan de carrera.

Palabras clave: Trabajo docente. Jornada de trabajo. Educación básica. Ley del Piso.

\title{
Introdução
}

$\mathrm{E}$ m 2008 foi aprovada a Lei no 11.738 (BRASIL, 2008), que estabeleceu o Piso Salarial Profissional Nacional (PSPN) aos professores da educação básica das redes públicas de ensino. Tratou-se da fixação da menor remuneração a ser paga a um servidor público que estiver atuando como professor da educação básica, com formação em nível de ensino médio (curso de magistério), por uma jornada semanal de no máximo 40 horas $^{2}$ Além da remuneração, também foi estabelecida a composição da jornada de 
trabalho, isto é, o percentual de horas dedicadas às atividades de interação direta com os alunos e aquelas dedicadas às atividades de apoio à docência.

Com isso, todas as redes de ensino públicas (municipais e estaduais) deveriam adotar uma composição da jornada que respeitasse a especificidade do trabalho do professor - que se desdobra além da sala de aula. Trata-se de um reconhecimento legal de que uma parte do trabalho docente ocorre fora da sala de aula, em atividades de preparação, correção de provas e atividades dos estudantes, atendimento aos pais e responsáveis, trabalho coletivo na escola, estudos etc. Assim, a partir da Lei do Piso, caberia à cada rede pública de ensino reestruturar seus planos de carreira, de forma a garantir em lei a composição máxima de $2 / 3$ da jornada com atividades diretas com os alunos e, no mínimo, 1/3 com aquelas de apoio à docência.

Após a aprovação da Lei do Piso, os governadores dos estados do Ceará (CE), Mato Grosso do Sul (MS), Paraná (PR), Rio Grande do Sul (RS) e Santa Catarina (SC) ajuizaram a Ação Direta de Inconstitucionalidade (ADI) no 4.167, contra a referida Lei, alegando que ela feria a autonomia federativa. A finalização do julgamento da ADI ocorreu somente em 2011, por meio do Acórdão do Supremo Tribunal Federal (STF/2011), que reconheceu a legalidade da Lei do PSPN na íntegra, determinando aos estados o seu cumprimento a partir daquele ano.

Entretanto, os estados do CE, MS, RS e SC entraram com recurso (embargos de declaração), requerendo mais 18 meses, da data do julgamento, para início do pagamento do PSPN. Dessa forma, a batalha judicial só findou em 2013, quando o STF decidiu pelo pagamento do PSPN a partir de 27 de abril de 2011, data do julgamento definitivo pelo plenário do STF. Caberia aos estados que não estavam pagand o o PSPN fazê-lo de forma retroativa à data da decisão do STF e cumprir a Lei do Piso.

O PSPN foi uma conquista da luta dos trabalhadores da educação em dois aspectos: pelo estabelecimento de um valor abaixo do qual nenhum ente federado poderia contratar professor para trabalhar na educação básica; e pela composição da jornada de trabalho, que compreende as horas relativas às atividades de apoio à docência. Contudo, o valor do Piso ficou aquém daquele reivindicado pela Confederação Nacional dos Trabalhadores em Educação (CNTE), assim como o número de horas para atividades de apoio à docência ${ }^{3}$. Em relação à composição da jornada, a reivindicação histórica do magistério é que $50 \%$ da jornada seja destinada às atividades de apoio à docência, independentemente de a jornada ser parcial ou integral (NORONHA, 2016). Assim, o percentual de $1 / 3$ representa um ganho em relação aos $20 \%$ ou menos de horas atividades que eram pagas aos professores, anteriormente à lei, mas não contempla a reivindicação histórica da categoria docente.

A luta por condições de trabalho adequadas não se encerrou com o estabelecimento em lei do mínimo de $1 / 3$ da jornada de trabalho para atividades de apoio à docência, ela continua na reivindicação para que os entes federados reestruturem os planos de 
carreira e cumpram efetivamente a Lei do Piso. Este artigo tem como objetivo contribuir com a discussão sobre a efetivação do PSPN, no que se refere à jornada de trabalho, a partir de levantamento da composição da jornada docente, com base nos planos de carreira e legislação dos professores da educação básica das redes estaduais de ensino, em vigor no ano de 2016. Buscamos verificar, de acordo com o estabelecido na legislação, se os planos de carreira dos professores dessas redes foram reestruturados para atender o prescrito na Lei do Piso no aspecto relacionado à composição da jornada de trabalho docente. Alertamos que não houve verificação in loco para saber se o previsto na legislação estava sendo efetivamente cumprido.

Em termos metodológicos foi desenvolvida pesquisa documental e bibliográfica, sendo os planos de carreira dos professores das redes de ensino dos 27 estados e do Distrito Federal os principais documentos de coleta de dados. De acordo com Lakatos \& Marconi (2001), a pesquisa documental trabalha com fontes primárias e a bibliográfica com fontes secundárias. Neste estudo, as fontes primárias são os planos de carreira, que forneceram as seguintes informações: quantidade, duração e composição das jornadas, que foram analisadas à luz da Lei do PSPN e da literatura sobre o tema.

O artigo está dividido em dois tópicos, além desta introdução e das considerações finais. No primeiro, discutimos brevemente a jornada de trabalho docente em diálogo com a literatura; no segundo são apresentados e analisados os dados da pesquisa, com indicação do cumprimento da Lei do Piso no que se refere à composição da jornada de trabalho; e, nas considerações finais, são apresentados alguns desafios ao cumprimento da lei e a importância de novos estudos, especialmente aqueles que permitam verificar se o previsto na legislação está sendo efetivado nas redes de ensino.

\section{Jornada de trabalho docente}

Nas sociedades capitalistas, o estabelecimento da duração da jornada de trabalho é resultado de disputas e negociações entre capital e trabalho. De acordo com Marx (1999), no processo de trabalho, ultrapassado o tempo necessário para o trabalhador produzir valor equivalente ao que recebe como salário, haverá produção de mais-valia ${ }^{4}$, elemento fundante do modo de produção capitalista; por isso a determinação da duração e da intensidade da jornada ${ }^{5}$ de trabalho figura como uma das principais reivindicações dos trabalhadores e está entre aquelas de maior dificuldade de negociação com o capital.

Dessa forma, a duração da jornada de trabalho dos trabalhadores do setor privado, historicamente determinada, influencia o estabelecimento da jornada de trabalho dos servidores públicos e, consequentemente dos professores, que, além das particularidades do trabalho docente, é definida com base no legalmente estabelecido para o conjunto dos demais trabalhadores. 
Em termos genéricos, jornada de trabalho é o termo utilizado para referir-se à extensão do trabalho medida em dia, semana, mês (DIEESE, 2003). Contudo, a jornada de trabalho não diz respeito somente à extensão, mas também à composição e à intensidade. No que se refere à docência, a composição da jornada é aspecto fundamental porque o trabalho do professor não se restringe à aula propriamente dita, ele se estende além da sala de aula num conjunto de atividades de apoio necessário à realização do processo educativo.

É comum encontrarmos na literatura uma compreensão de que a jornada de trabalho se refere ao período em que o empregado permanece à disposição de seu empregador (RIBEIRO, 2014), de modo geral em local determinado para realização de suas funções. Conquanto, as novas tecnologias têm permitido, por um lado, que alguns profissionais realizem parte ou a totalidade de seu trabalho em sua própria casa, dando a eles certa liberdade em relação aos horários de realização das tarefas que devem ser cumpridas em determinado período; por outro, está cada vez mais difícil separar o período de trabalho daquele de descanso, lazer e convivência social. O celular permanentemente ligado e a conexão à internet têm contribuído para embaralhar os tempos de trabalho e não-trabalho, fazendo com que o trabalhador esteja em constante prontidão para atender seus empregadores. Assim, novas configurações de trabalho são produzidas e atingem de forma diversa todos aqueles que vivem da venda da força de trabalho.

A duração da jornada de trabalho no Brasil não deve ser maior que oito horas diárias e 44 horas semanais, de acordo com o Art. $7^{\circ}$ da Constituição Federal de 1988 (CF/88) (BRASIL, 1988), que trata dos direitos dos trabalhadores urbanos e rurais. Ainda, conforme Art. 37, é permitido aos professores o acúmulo de dois cargos de professor ou um cargo de professor com outro técnico ou científico. Dessa forma, o acúmulo de cargo permite que os professores trabalhem mais que as 44 horas semanais previstas na CF/88. Há situações, a exemplo da rede municipal de ensino de São Paulo, em que a legislação permite uma jornada de até 70 horas semanais, quando em acúmulo de cargo (SÃO PAULO, 2007). Na análise de Arelaro et. al (2014, p. 203), "não restam dúvidas de que 70 horas semanais de trabalho são incompatíveis com um bom desempenho profissional e representam um absoluto desrespeito ao trabalhador". Nesse contexto, o acúmulo de cargo é resultado dos baixos salários, que obrigam o professor a trabalhar em mais de uma rede de ensino ou em dois cargos na mesma rede para garantir uma remuneração que lhe permita a sobrevivência, por isso, muitas vezes o acumulo é reivindicado pelos professores como um direito.

Estudo da Organização das Nações Unidas para a Educação, a Ciência e a Cultura (Unesco), de 2008, sobre as condições de trabalho dos professores da educação básica em diversos países, citado por Ribeiro (2014), afirma que cerca de 30\% dos professores dão aula em mais de uma escola com jornada semanal de 46 horas e $70 \%$ dos professores trabalham em torno de 33 horas semanais. Informa ainda que a jornada daqueles que trabalham em mais de uma escola é de 46 horas semanais e que menos de $1 / 4$ é destinada às atividades de apoio à docência. 
Pesquisa conduzida por Alves e Pinto (2011) sobre características do trabalho docente, com base nos dados da Pesquisa Nacional por Amostra de Domicílios (Pnad) de 2009, revela informações interessantes sobre a jornada de trabalho do professor no Brasil. A partir da ressalva de que o questionário da Pnad não permite saber se a jornada informada pelo professor contempla as horas dedicadas às atividades de apoio à docência, mas acreditando que o mais provável é que o professor tenha informado apenas o número de aulas que ministra semanalmente, os autores verificaram que $27,1 \%$ dos professores trabalhavam em jornada parcial, ou seja, entre 20 e 25 horas semanais, 36,6\% em jornada integral de 40 horas semanais e que 51,3\% dos professores da educação básica tinham uma jornada igual ou superior a 40 horas semanais.

A pesquisa de Cação (2001) sobre jornada de trabalho dos professores da educação básica da rede estadual paulista indica que, desde os anos de 1970, eles reivindicam a jornada única de trabalho como forma de fixar o professor em um exclusivo local de trabalho e garantir melhores condições para o desenvolvimento de um processo educativo de melhor qualidade.

Esses dados sugerem que as condições de trabalho do professor, no que se refere à duração e à composição da jornada, não têm contribuído para o desenvolvimento de um trabalho pedagógico com qualidade, tanto em relação à extensão da jornada quanto à composição que nem sempre contemplam as horas de trabalho necessárias à realização das atividades de apoio à docência, obrigando o professor a realizar trabalho não pago para garantir um mínimo de qualidade ao trabalho educativo.

Dadas as características do trabalho docente, é fundamental que a jornada pela qual o professor recebe uma remuneração compreenda as horas-aula e as horas relativas às atividades de apoio à docência. Se apenas as aulas forem computadas para efeito do estabelecimento da jornada, significará que o professor desenvolverá um conjunto de atividades concernentes à docência sem remuneração. Da mesma forma, se a parte da jornada destinada às atividades de apoio à docência for muito pequena, o professor dispenderá horas de trabalho sem remuneração. A parte da jornada do professor destinada às atividades de apoio à docência pode ser dividida entre o trabalho coletivo para elaboração e desenvolvimento do projeto educacional da escola, comumente realizada na escola, e o trabalho individual de preparação de aula, correção de provas etc., que pode ser desenvolvido em diferentes locais, inclusive na casa do professor.

Concernente às reivindicações e lutas do magistério, nos anos 2000, o Conselho Nacional de Educação, por meio do Parecer nº 9/2009 da Câmara de Educação Básica $($ BRASIL, 2009a), indicou a dedicação exclusiva do professor a uma única unidade escolar como instrumento importante à qualificação e realização do projeto político-pedagógico. Na Resolução nº 2 do CNE/CEB (BRASIL, 2009b), que fixa as diretrizes nacionais para os Planos de Carreira, foi estabelecido: 
Jornada de trabalho preferencialmente em tempo integral de, no máximo, 40 (quarenta) horas semanais, tendo sempre presente a ampliação paulatina da parte da jornada destinada às atividades de preparação de aulas, avaliação da produção dos alunos, reuniões escolares, contatos com a comunidade e formação continuada, assegurando-se, no mínimo, os percentuais da jornada que já vêm sendo destinados para estas finalidades pelos diferentes sistemas de ensino, de acordo com os respectivos projetos político-pedagógico (BRASIL, 2009b, art. 4⿳⺈, inciso VII).

No ano anterior, a Lei do Piso havia estabelecido que "na composição da jornada de trabalho, observar-se-á o limite máximo de $2 / 3$ (dois terços) da carga horária para 0 desempenho das atividades de interação com os educandos" (Art. $2^{2} \S 4^{\circ}$. Por analogia, compreende-se que, no mínimo, $1 / 3$ da jornada deve ser dedicada àquelas atividades de apoio à docência. Dessa forma, o Parecer apresenta uma recomendação genérica que propõe a ampliação sem estabelecer uma proporção que poderia ser considerada ideal ou pelo menos mais adequada para atender o conjunto de atividades que o professor realiza, além do tempo em que ministra as aulas.

Tendo em vista que a Lei do Piso é a legislação mais precisa sobre a composição da jornada dos professores da educação básica, os planos de carreira e a legislação concernente dos estados serão analisados com o intuito de averiguar se a Lei do PSPN estava sendo cumprida, no que se refere à composição da jornada e ao máximo de 40 horas semanais de trabalho.

\section{Jornada de trabalho docente nos estados}

Para verificar o cumprimento da composição da jornada docente, de acordo com o PSPN, procedemos à análise dos planos de carreira dos estados em vigor no ano de 2016. É importante notar que a CNTE realiza levantamentos semelhantes relativos às redes estaduais, com sistemática e dinâmicas próprias da ação sindical. Pesquisa de Masson (2016) sobre o cumprimento da Lei do Piso nos aspectos relacionados à remuneração e à composição da jornada também apresenta dados que não coincidem exatamente com os aqui apresentados, que tem como referência as legislações estaduais em vigor no ano de 2016.

Na Tabela 1 apresentamos a duração e a composição das jornadas prevista na legislação consultada, indicamos o ano de aprovação do plano de carreira e se a referida legislação estava em conformidade com a Lei do PSPN. 
Tabela 1 - Duração e composição das Jornadas de trabalho dos professores da educação básica dos estados e Distrito Federal - 2016

\begin{tabular}{|c|c|c|c|}
\hline Estado & $\begin{array}{l}\text { Composição das Jornadas } \\
\text { Carga horária da jornada (horas de interação com } \\
\text { alunos + horas sem interação com alunos = \% } \\
\text { interação com alunos) }\end{array}$ & $\begin{array}{l}\text { Cumpre } \\
\text { a lei do } \\
\text { Piso? }\end{array}$ & $\begin{array}{l}\text { Ano de } \\
\text { Aprovação } \\
\text { do Plano } \\
\text { de Carreira }\end{array}$ \\
\hline AC & $\begin{array}{l}16(11+5=68,75) 20(13+7=65) 25(17+8=68) 30 \\
(20+10=66,66) 40(27+13=67,5)\end{array}$ & Parcialmente & 2013 \\
\hline $\mathrm{AL}$ & $\begin{array}{l}20(15+5=75) 25(20+5=80) 30(23+7=76,66) 40(30+10=75) \\
40(28+12=70) 20(16+4=80)\end{array}$ & Não & 2005 \\
\hline AM & $20(13+7=65) 30(20+10=66,66) 40(27+13=67,5)$ & Parcialmente & 2013 \\
\hline AP & $20(12+8=60) 30(18+12=60) 40(24+16=60)$ & Sim & 2013 \\
\hline BA & Sem especificações & Não & 2011 \\
\hline $\mathrm{CE}$ & $20(13+7=65) 40(26+14=65)$ & Sim & 1993 \\
\hline DF & $20(13+7=65) 40(25+15=62,5)$ & Sim & 2013 \\
\hline ES & $25(20+5=80)$ & Não & 1998 \\
\hline GO & $20(14+6=70) 30(21+9=70) 40(28+12=70)$ & Não & 2014 \\
\hline MA & $20(13+7=65) 40(26+14=65)$ & Sim & 2013 \\
\hline MG & $24(16+8=66,66)$ & Sim & 2012 \\
\hline MS & $20(15+5=75) 40(30+10=75)$ & Não & 2012 \\
\hline MT & $30(20+10=66,66)$ & Sim & 1998 \\
\hline PA & $20(15+5=75) 30(22+8=73,33) 40(30+10=75)$ & Não & 2014 \\
\hline PB & $25(20+5=80) 35(20+15=57,14)$ & Parcialmente & 2003 \\
\hline PE & $30(24+6=80) 40(32+8=80) 30(21+9=70) 40(28+12=70)$ & Não & 1996 \\
\hline PI & $20(14+6=70) 40(28+12=70)$ & Não & 2006 \\
\hline PR & $20(13+7=65) 40(26+14=65)$ & Sim & 2004 \\
\hline RJ & Sem especificações & Não & 1990 \\
\hline RN & $30(24+6=80) 40(32+8=80)$ & Não & 2014 \\
\hline RO & $\begin{array}{l}20(20+0=100) 25(20+5=80) 40(20+20=50) 20(13+7=65) 25 \\
(17+8=68) 40(27+13=67,5)\end{array}$ & Parcialmente & 2012 \\
\hline $\mathbf{R R}$ & $25(16+9=64)$ & Sim & 2013 \\
\hline RS & $20(13+7=65)$ & Sim & 1974 \\
\hline SC & $10(8+2=80) 20(16+4=80) 30(24+6=80) 40(28+12=70)$ & Não & 2015 \\
\hline SE & $125(78+47=62,4) 200(150+50=75)$ & Parcialmente & 2001 \\
\hline SP & $12(9+3=75) 24(19+9=79,16) 30(24+12=80) 40(32+16=80)$ & Não & 1997 \\
\hline TO & $20(12+8=60) 40(24+16=60)$ & Sim & 2014 \\
\hline
\end{tabular}


Fonte: Elaborada pelos autores com base em: Acre (2013), Alagoas (2005), Amazonas (2013), Amapá (2013), Bahia (2011), Brasília (2013), Ceará (1993), Espírito Santo (1998), Goiás (2014), Maranhão (2013), Minas Gerais (2012), Mato Grosso do Sul (2012), Mato Grosso (1998), Pará (2014), Paraíba (2003), Pernambuco (1996), Piauí (2006), Paraná (2004), Rio de Janeiro (1990), Rio Grande do Norte (2014), Rondônia (2012), Roraima (2013), Rio Grande do Sul (1974, 1985, 2012, 2016), Santa Catarina (2015), Sergipe (2001), São Paulo (1997, 2012), Tocantins (2014).

Obs 1: Com a Resolução n. 8 de 19/01/2012 o governo do estado de São Paulo informa que está cumprindo a Lei n. 11.738/2008, ao considerar que as aulas são de 50 minutos e a jornada corresponde a 40 horas de 60 minutos. Ele considera que estes 10 minutos compõem a parte da jornada dedicada às atividades de apoio à docência.

Obs 2: Encontra-se disposto na Lei 8.261 de 29/05/2002, art. 53, do estado da Bahia, que o docente da $1^{\mathrm{a}}$ a $4^{\mathrm{a}}$ série do ensino do ensino fundamental, submetido ao regime de tempo parcial ou integral com efetiva regência de classe, receberá uma gratificação de $15 \%$ (quinze por cento) sobre o seu vencimento básico, a título de atividades complementares, que passará a ser de $27 \%$ (vinte e sete por cento) a partir de $1^{2}$ de janeiro de 2003.

Obs 3: No Rio Grande do Sul, apesar das normas locais apontarem para o cumprimento da jornada prevista na Lei do Piso, na implementação os professores dos anos iniciais do ensino fundamental, de fato, não gozam o direito de ter o máximo de 2/3 da jornada em atividades de interação com educandos. Esse caso está em disputa na justiça.

Obs. 4: Se o leitor comparar esta tabela com os dados da CNTE de 2016 verá que em 16 estados há interpretação diferente em relação ao cumprimento da Lei do Piso no que se refere à composição da jornada de trabalho; isso ocorre, conforme informado anteriormente, porque a forma de coleta dos dados é diferente. No caso deste artigo, utilizamos as informações que constam no plano de carreira, sem a verificação in loco sobre o cumprimento da Lei. A título de exemplo citamos o caso da rede estadual do Piauí, onde, apesar de não ter efetivado modificações legais no Plano de Carreira para adequá-lo aos dispositivos da Lei do PSPN em relação à distribuição da jornada, docentes da rede de ensino e o Sindicato dos Trabalhadores e Trabalhadoras da Educação Pública Básica do Estado do Piauí (SINTE-PI) informam que a rede garante 1/3 da jornada para as atividades de apoio à docência, portanto, cumpre a Lei do Piso, tal como informado no site da CNTE.

A duração da jornada de trabalho docente é bastante diversa nas redes de ensino, conforme já constatado em trabalho de Gil, Trein e Wolker (2016). São encontradas 11 diferentes jornadas, em termos da quantidade de horas $(10,12,16,20,24,25,30,35$ e 40 semanais, além de 125 e 200 horas mensais em Sergipe).

Apesar do grande número de jornadas, em 16 planos de carreira estavam previstas apenas uma ou duas jornadas. Em 11 planos, somente duas jornadas; em cinco estados, estava prevista apenas uma jornada; em outras cinco unidades da federação figuravam três jornadas; e a rede do Acre foi a que apresentou o maior número de jornadas: 5 . As jornadas de 40, 30 e 20 horas eram as mais presentes nos planos. A de 40 horas em 20 planos, o que correspondia a $74 \%$ dos estados, a de 20 horas em 17 planos (63\%) e a de 30 horas em 11 planos ( $41 \%)$. Se considerarmos como jornadas parciais aquelas cuja duração é de até 25 horas semanais, observamos que apenas quatro planos previam somente jornadas parciais.

Diferentemente da jornada de tempo integral, com o máximo de quarenta horas semanais e incentivo à dedicação exclusiva indicada no parecer do CNE/CEB no 9/2009 (BRASIL, 2009a), o que encontramos foi uma diversidade de duração das jornadas de trabalho docente.

Após oito anos da aprovação do PSPN e seis do reconhecimento de sua constitucionalidade pelo Supremo Tribunal Federal, das 27 unidades federativas encontramos 12 (AL, BA, ES, GO, MS, PA, PE, PI, RJ, RN, SC e SP) que não cumpriam a divisão de 2/3 e 1/3 para todas as jornadas; outros 10 (AP, CE, DF, MA, MG, MT, PR, RR, TO e RS) que cumpriam e cinco estados (AC, AM, RO, SE e PB) que cumpriam parcialmente, isto é, nem todas as jornadas tinham a composição com o máximo de 2/3 da carga horária em atividade de interação com estudantes, de acordo com os planos de carreira consultados. Não estava especificado nas legislações consultadas da Bahia e do Rio de Janeiro o percentual da jornada destinado à aula e às atividades de apoio à docência. É notável que, em 2016, apenas 37\% dos planos dos estados previam para todas as jornadas a proporção máxima de $2 / 3$ da jornada para as atividades de interação com alunos. 
Esse descumprimento da Lei do Piso, no que se refere à composição da jornada, tem implicações nas condições de trabalho do professor e, potencialmente, na qualidade do ensino. Portanto, o cumprimento da Lei diz respeito não somente aos direitos trabalhistas do professor, mas à educação de qualidade que todo estudante tem direito.

Visto que na maioria dos planos não estava previsto o mínimo de $1 / 3$ da jornada para atividades de apoio à docência para todas as jornadas, procedemos à verificação do percentual de cada jornada que é destinado a essas atividades.

Os dados informam que nos planos ${ }^{6}$ de dois estados (MT, MG) estavam previstas jornadas com a composição de exatamente $1 / 3$ para atividades de apoio à docência, mínimo previsto na Lei do Piso. Além desses estados, há aqueles que apresentavam, em seus planos, jornadas com percentuais acima de $1 / 3$ para as atividades de apoio à docência. Esses percentuais variavam de 35\% a 50\% (AC, AM, AP, CE, DF, MA, PR, RO, RR, RS, SE e TO).

É importante observar que em 12 planos há jornadas com percentuais acima do mínimo previsto na Lei do Piso para as atividades de apoio à docência. Em Rondônia esse percentual chega a 50\%, o mesmo reivindicado pela CNTE. Mas é necessário destacar que o percentual de $50 \%$ é somente para uma das jornadas de 40 horas semanais, havendo outras jornadas com percentuais menores.

Não obstante esses avanços, nos planos de carreira de 11 estados (AL, ES, GO, MS, PA, PB 7 , PE, PI, RN, SC, SP) há percentuais da jornada destinados às atividades de apoio à docência que variam apenas entre $20 \%$ e 30\%. Soma-se a isso o fato de que nos estados da Paraíba, Rondônia e Sergipe os percentuais são diferenciados de acordo com a duração da jornada. Apesar de na Lei do Piso a jornada de referência ser de 40 horas semanais, entende-se que o percentual mínimo de $1 / 3$ para as atividades de apoio à docência deve ser aplicado a todas as jornadas, independentemente da duração e da etapa da educação na qual o professor atua. Trata-se de uma compreensão de que o trabalho do professor se estende além da sala de aula e isso independe da quantidade de aulas que ele ministra semanalmente ou da etapa de ensino em que leciona. Conquanto, não foi isso que encontramos em todos os planos. Em onze há percentuais diferentes de horas para atividades de apoio à docência para as distintas jornadas.

Em relação ao ano de aprovação do plano de carreira, observamos que 12 são anteriores a 2008; destes, quatro cumprem, dois cumprem parcialmente e seis não cumprem a Lei do Piso. Entre os 15 planos aprovados após 2008, há seis que cumprem, três que cumprem parcialmente e seis que não cumprem o PSPN. Ou seja, mesmo em planos aprovados após 2008, a Lei do Piso seguia não sendo acatada. 


\section{Algumas considerações para finalizar}

Analisamos neste artigo em que medida a Lei do PSPN estava sendo cumprida nos planos de carreira dos professores das redes estaduais de ensino no que se referia à composição da jornada de trabalho. Partimos da compreensão de que o trabalho docente requer uma jornada de trabalho que contemple horas destinadas à atividade de interação com os alunos e horas destinadas às atividades de apoio à docência, numa proporção de no máximo $2 / 3$ de atividades com os alunos, conforme estabelecido no PSPN. Consideramos também que o ideal seria o professor trabalhar em jornada de tempo integral de, no máximo, 40 horas em dedicação exclusiva, de forma que pudesse dedicar-se integralmente a uma rede de ensino e uma escola.

O que encontramos ao analisar os planos de carreira dos estados e legislação concernente, no ano de 2016, foi o descumprimento da proporção $2 / 3-1 / 3$ na composição de todas as jornadas, na maioria dos planos. Isso significa que o cumprimento da Lei do PSPN ainda é um desafio aos entes federados e uma necessidade à melhoria de condições de trabalho do professor. Compreende-se ainda que a enorme diversidade das jornadas estaduais (11 cargas horárias distintas) compõe um quadro complexo e ainda em configuração, o qual exige acompanhamento e novos estudos.

As dificuldades orçamentárias dos estados para cumprir a Lei do Piso, seja em relação ao valor mínimo do vencimento base estabelecido, seja em relação à composição da jornada, poderiam ser superadas com a ajuda da União, conforme estabelecido na Lei nº 11.738/2008 (BRASIL, 2008). No entanto, há empecilhos normativos que inviabilizam o acesso ao apoio federal por estados que, por exemplo, estejam excluídos da complementação da União ao Fundeb. Afora essas limitações impostas pela própria Lei para os estados recorrerem à ajuda da União, a Emenda Constitucional nº 95/2016 (BRASIL, 2016), que institui novo regime fiscal, acarretará sérias dificuldades para os entes federados cumprirem a Lei do Piso, indicando que os insuficientes avanços na valorização docente alcançados nos últimos anos poderão retroceder, piorando as condições de trabalho do professor e influenciando negativamente a qualidade da educação.

Nesse contexto, será necessária organização e unidade na luta do magistério público para impedir retrocessos na legislação e garantir que ela seja cumprida, sem abandonar a perspectiva de que a valorização docente ainda demanda avanços na legislação. Trata-se de uma tarefa eminentemente das organizações sindicais que pode receber das pesquisas acadêmicas, dados e análises que confluam para a compreensão mais ampla das condições de trabalho do magistério público.

No que se refere à jornada de trabalho do professor, diante da diversidade em sua duração, parece ser importante o estabelecimento de jornadas que contemplem as especificidades do trabalho docente, mas que estejam em consonância com a organização e funcionamento das escolas. Se, por um lado, detectou-se que a jornada de 40 horas 
semanais está presente em 18 dos 27 planos analisados, por outro, as jornadas com poucas horas semanais sinalizam uma relação precária do professor com a rede de ensino e com a escola, consequentemente, com o projeto educativo, favorecendo o acúmulo de cargo, o que pode significar muitas horas de trabalho por semana, assim como jornadas que ultrapassam as 40 horas semanais.

Consideramos que a Lei do Piso, no que se refere ao estabelecimento da composição da jornada, significou um avanço em relação à situação anterior, em que não havia nenhum parâmetro em âmbito nacional para induzir os entes federados a garantirem percentual da jornada para as atividades de apoio à docência. Entretanto, os dados desta pesquisa denunciam que a Lei não está sendo cumprida integralmente na maioria dos estados, comprometendo, dessa forma, o potencial da legislação em propiciar melhores condições de trabalho ao professor e influenciar positivamente nas condições de ensino aos estudantes.

Recebido em: 09/01/2019 e aprovado em: 01/05/2019

\section{Notas}

1 Este artigo foi elaborado com base em pesquisa financiada pela Capes - Edital OBEDUC 2012.

2 Naquele ano e em 2009, o valor do Piso foi de R 950,00. Em 2018 foi de R\$2.455,35.

3 Para mais análises acerca das lutas pelo PSPN, consultar as teses de doutorado de João Antônio Cabral de Monlevade e Juçara Dutra Vieira.

4 Marx chama de mais-valia absoluta aquela produzida pelo prolongamento da duração do trabalho excedente e mais-valia relativa aquela decorrente da contração do tempo de trabalho necessário e a correspondente alteração na relação quantitativa entre as duas partes da jornada de trabalho, a que produz valor equivalente ao salário do trabalhador e aquela em que há produção de mais-valia. Trabalho necessário diz respeito ao tempo de trabalho necessário à sobrevivência do trabalhador, à produção de um valor que corresponde ao seu salário. O trabalho excedente é aquele que produz valor para além do necessário para manutenção da força de trabalho, o valor produzido pelo trabalho excedente é apropriado pelos donos dos meios de produção, é o que Marx denomina de mais-valia.

5 Sobre intensificação do tempo de trabalho ver Cardoso (2013).

6 Como um mesmo plano tem mais de uma jornada e composições diferenciadas para a mesma jornada, os números apresentados não correspondem ao número de estados.

7 Paraíba cumpre a Lei no caso da jornada de 35 horas, conforme Tabela 1. 


\section{Referências}

ACRE. Lei no 274 de 9 de janeiro de 2013.

ALAGOAS. Lei n⿳0 6.588, de 5 de abril de 2005.

ALVES, Thiago. PINTO, José Marcelino de Rezende. Remuneração e características do trabalho docente no Brasil: um aporte. Cadernos de Pesquisa. v. 41, n. 143, maio/ago. 2011.

AMAPÁ. Lei no 1743, de 29 de abril de 2013.

AMAZONAS. Lei no 3951 de 04 de novembro de 2013.

ARELARO, L. R. G. et al. Condições de trabalho docente: uma análise da carreira na rede municipal de ensino de São Paulo. Revista Brasileira de Estudos Pedagógicos, Brasília, v. 95, n. 239, p. 199-217.

BAHIA. Lei 12.046 de 04 de janeiro de 2011.

BRASIL. Constituição da República Federativa do Brasil de 1988.

Lei n⿳⺈ 11.738 , de 16 de julho de 2008.

de $2009 \mathrm{~b}$.

Conselho Nacional de Educação. Câmara da Educação Básica. Resolução n⿳o 2, de 28 de maio

BRASIL. Conselho Nacional de Educação. Câmara da Educação Básica. Parecer $\mathbf{n}^{\circ}$ 02, de 02 de abril de 2009a.

. Emenda Constitucional nº 95, de 15 de dezembro de 2016.

BRASÍLIA (DF). Lei nº 5105 de 03 de maio de 2013.

CAÇÃO, M. I. Jornada de trabalho docente: delineamento histórico da organização do trabalho do magistério público estadual paulista. Tese (Doutorado em Educação). Faculdade de Educação. Universidade Estadual de Campinas. Campinas, 2001.

CARDOSO, A. C. M. Organização e intensificação do tempo de trabalho. Revista Sociedade e Estado, vol. 28, n. 2, p. 351-374, maio/agosto, 2013.

CEARÁ. Lei no 12.066, de 13 de janeiro de 1993.

CONFEDERAÇÃO NACIONAL DE TRABALHADORES EM EDUCAÇÃO (CNTE). Piso e carreira andam juntos para valorizar os profissionais da educação básica pública.

DEPARTAMENTO INTERSINDICAL DE ESTATÍSTICA E ESTUDOS SOCIOECONÔMICOS (DIEESE). Jornada de trabalho em países selecionados. Meta II - relatórios. Convênio SE/TEM no 04/2003-Dieese.

ESPÍRITO SANTO. Lei n⿳0 5580 de 13 de janeiro de 1998.

GIL, Juca; TREIN, Laura DEXHEIMER; WOLKER, Luiz Celso SÁ FRONCKOWIAK. Planos de carreira docente no Brasil: uma análise das jornadas de trabalho e sua composição nas redes estaduais de ensino a partir da lei nº 11.738/08. Anais 4º Encontro Fineduca, p. 995-1009, 2016.

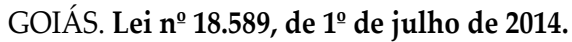


LAKATOS, E. M. \& MARCONI, A. Metodologia do Trabalho Científico: procedimentos básicos, pesquisa bibliográfica, projeto e relatório, publicações e trabalhos científico. São Paulo: Atlas, $6^{a}$ ed., 2001.

MARANHÃO. Lei no 9860 de $1^{\circ}$ de julho de 2013.

MASSON, Gisele. A valorização dos professores e a educação básica nos estados. Retratos da Escola, v. 10, p. 157-174, 2016.

MATO GROSSO. Lei Complementar n⿳ํ50, de $1^{0}$ de outubro de 1998.

MATO GROSSO DO SUL. Lei complementar no 165, de 25 de outubro de 2012.

MINAS GERAIS. Lei no 20592, de 28 de dezembro de 2012.

MARX, Karl. O capital: crítica da economia política. Livro 1, volume 1. 17ª ed. Rio de Janeiro: Civilização Brasileira, 1999.

MONLEVADE, João Antonio CABRAL DE. Valorização salarial dos professores: o papel do Piso Salarial Profissional Nacional como instrumento de valorização dos professores da educação básica pública. Tese (Doutorado em Educação) - Faculdade de Educação, Universidade Estadual de Campinas, Campinas, 2000.

NORONHA, M. I. A. Diretrizes nacionais de carreira e PSPN: novos marcos aos profissionais da educação. Revista Retratos da Escola, Brasília, v. 10, n.18, p. 57-73, jan.jun. 2016.

PARÁ. Lei no 8.030 de 21 de julho de 2014.

PARAÍBA. Lei no 7.419, de 15 de outubro de 2003.

PARANÁ. Lei no 103 de 15 de março de 2004.

PERNAMBUCO. Lei no $\mathbf{1 1 . 3 2 9}$ de 16 de janeiro de 1996.

PIAUÍ. Lei no 71 de julho de 2006.

RIBEIRO, J. M. C. A jornada de trabalho dos professores da escola pública em contexto de políticas de valorização docente e qualidade da educação. Tese (Doutorado em Educação). Faculdade de Educação da Universidade Federal do Rio Grande do Sul. RS, 2014.

RIO DE JANEIRO. Lei no 1.614 , de 24 de janeiro de 1990.

RIO GRANDE DO NORTE. Lei Complementar nº 507, de 28 de março de 2014.

RIO GRANDE DO SUL. Lei n⿳o 6.672, de 22 de abril de 1974.

. Lei no 8.112, de 24 de dezembro 1985.

Decreto $\mathrm{n}^{0}$ 49.448, de 08 de agosto de 2012.

. Decreto $\mathrm{n}^{0}$ 52.921, de 23 de fevereiro de 2016.

RONDÔNIA. Lei Complementar n⿳o 680, de 7 de setembro de 2012.

RORAIMA. Lei $\mathrm{n}^{0}$ 892, de 25 de janeiro de 2013.

SANTA CATARINA. Lei Complementar n⿳0 668, de 28 de dezembro de 2015.

SÃO PAULO. Lei Complementar no 836, de 30 de dezembro de 1997. 
Resolução SE no 08, de 19 de janeiro de 2012.

(capital). Lei $\mathrm{n}^{\mathrm{0}}$ 14.660, de 26 de dezembro de 2007.

SERGIPE. Lei complementar $n^{\circ}$ 61, de 16 de julho de 2001.

SUPREMO TRIBUNAL FEDERAL. Ação Direta de Inconstitucionalidade nº 4.167. Distrito Federal. Brasília, 2011.

TOCANTINS. Lei n⿳0 2.859, de 30 de abril de 2014 .

VIEIRA, Juçara Maria DUTRA. Piso salarial para os educadores brasileiros: quem toma partido? 2012. xviii, 276 f., il. Tese (Doutorado em Educação) - Universidade de Brasília, Brasília, 2012. Acesso em http://repositorio.unb.br/handle/10482/12059 